\title{
Helicobacter Pylori Eradication Therapy: Still a Challenge
}

Muhammad Hafeez ${ }^{1}$, Zafar A. Qureshi ${ }^{1}$, Abdul L. Khattak ${ }^{2}$, Farrukh Saeed ${ }^{1}$, Asma Asghar ${ }^{3}$, Khalid Azam $^{4}$, Muhammad A. Khan ${ }^{5}$

1. Gastroenterology, Pak Emirates Military Hospital, Rawalpindi, PAK 2. Medicine, Combined Military Hospital, Lahore, PAK 3. Gastroenterology, Combined Military Hospital, Lahore, PAK 4. Pulmonology, Combined Military Hospital, Lahore, PAK 5. Physiology, Army Medical College, Rawalpindi, PAK

Corresponding author: Muhammad Hafeez, hafeezm338@gmail.com

\section{Abstract \\ Introduction}

Helicobacter pylori (H. pylori) infection is prevalent worldwide. H. pylori therapies' adverse effects can contribute to noncompliance among patients. This study aimed to assess the association between compliance to $\mathrm{H}$. pylori eradication therapy and adverse effects using various drug regimens.

\section{Method}

We conducted an observational study from September 2017 to February 2020 in two tertiary care hospitals in patients with dyspeptic symptoms. H. Pylori detection was done by histopathological examination of gastric mucosa during upper gastrointestinal endoscopy or stool for H. pylori antigen. Patients with positive results were randomly assigned one of the nine different regimens consisting of a combination of proton pump inhibitors along with at least two antibiotics. The antibiotics used in different combinations were amoxicillin, clarithromycin, metronidazole, doxycycline, levofloxacin, and bismuth sulfate. The treatment groups received standard triple therapy with and without probiotics, sequential, concomitant, levofloxacinbased triple therapy, or sequential and bismuth-based quadruple treatments. All treatments were given for two weeks. At the end of the treatment period, patients were interviewed about completing treatment and any adverse effects they may have experienced during therapy. Data were analyzed using IBM Statistical Package for the Social Sciences (SPSS) Statistics for Windows, Version 22.0 (Armonk, NY: IBM Corp.).

\section{Results}

A total of 250 patients were included in the study ( $62 \%$ males, $38 \%$ females) with a mean age of 37 years \pm 13 years (range 12-84 years). Most patients completed the treatment regimen (80.4\%), and 19.6\% did not complete treatment because of adverse effects $(\mathrm{p}<0.005)$. The levofloxacin-based, concomitant, and standard triple regimen with probiotic treatments had the highest tolerance $(\geqslant 85 \%)$. Common adverse effects were abdominal and epigastric pain (11\%), alteration of taste, and diarrhea (6.5\%).

Review began 03/31/2021 Review ended 04/26/2021 Published 05/06/2021

\section{○ Copyright 2021}

Hafeez et al. This is an open access article distributed under the terms of the Creative Commons Attribution License CC-BY 4.0., which permits unrestricted use, distribution, and reproduction in any medium, provided the original author and source are credited.

\section{Conclusion}

H. pylori eradication therapy is always a challenge. Patient compliance to the treatment can only be ensured by medicines with fewer adverse effects. In our study, levofloxacin-based triple, concomitant, and standard triple regimens with probiotics are maximally acceptable treatments.

Categories: Internal Medicine, Gastroenterology

Keywords: drug regimens for h. pylori, helicobacter pylori, h pylori treatment challenges

\section{Introduction}

More than half of the world's population is suffering from infection with Helicobacter pylori (H. pylori), and given the improvement of sanitary standards, the prevalence of $H$. pylori infection varies widely in different parts of the world [1-3]. H. pylori is a Gram-negative bacterium that colonizes gastric mucosa. Its detection in 1983 revolutionized peptic ulcer treatment [4]. H. pylori has oral-to-oral and fecal-oral transmission. Parents and siblings play an important role in transmission [5].

The clinical features of $\mathrm{H}$. pylori infection vary from asymptomatic to mucosa-associated lymphoid tissue lymphoma. Common conditions associated with $\mathrm{H}$. pylori are acid peptic disease, idiopathic thrombocytopenic purpura, iron deficiency, and vitamin B12 deficiency [6]. H. pylori eradication therapy is recommended in patients who test positive [7]. Because $\mathrm{H}$. pylori infections are challenging to treat, combination therapy of at least two antibiotics and proton pump inhibitors (PPIs) are recommended [8].

The most common adverse effects of antibiotics are related to the GI system like abdominal pain, epigastric 


\section{Cureus}

pain, diarrhea, constipation, and metallic taste [9]. Other adverse effects are headaches with or without vomiting. Intolerance to the drugs due to their adverse effects leads to noncompliance with the treatment, culminating in treatment failure and resistance to these drugs. Several studies have been conducted on effective medicines, treatment outcomes, and possible adverse effects, but very few have quantified patients' ability to complete the treatment based on adverse effects [10-12]. We conducted this study to determine the association between patient compliance to $\mathrm{H}$. pylori eradication therapy and adverse effects using various drug regimens.

\section{Materials And Methods}

We conducted this observational study in Combined Military Hospital (CMH) Multan and Pak Emirates Military Hospital (PEMH) Rawalpindi tertiary care hospitals from September 2017 to February 2020. The study design was approved by the ethical committee of the hospitals. We used consecutive convenient sampling. All patients with dyspepsia due to H. pylori infections were included in the study after providing written informed consent. We excluded patients with dyspepsia secondary to other causes, patients treated with ongoing PPIs, and patients treated with antibiotics with anti-H. pylori effects. Pregnant ladies were also excluded due to the possible teratogenic effects of drugs. H. pylori was detected via histopathological examination of the gastric mucosal biopsy specimen taken during an upper GI endoscopy or via stool examination. Gastric biopsy specimens were stained with hematoxylin and eosin with and without Giemsa staining to detect spiral-shaped H. pylori organisms on histopathology. The detection of $\mathrm{H}$. pylori antigens in stool used an enzyme immunoassay qualitative or semiquantitative multiple-step method. Patients were assigned into nine groups randomly that were computed based on as specified in Table 1, and each group underwent a different treatment to observe for adverse effects and compliance.

\begin{tabular}{|l|l|}
\hline Serial no. & Drug regimens \\
\hline 1 & $\mathrm{PPI}+$ clarithromycin + amoxicillin (standard triple treatment) \\
\hline 2 & $\mathrm{PPI}+$ amoxicillin + metronidazole (standard triple treatment) \\
\hline 3 & $\mathrm{PPI}+$ bismuth + doxycycline + amoxicillin + nitroimidazole (bismuth-based quadruple treatment) \\
\hline 4 & $\mathrm{PPI}+$ clarithromycin + amoxicillin + nitroimidazole (concomitant treatment) \\
\hline 5 & $\mathrm{PPI}+$ clarithromycin + amoxicillin + nitroimidazole (concomitant treatment) \\
\hline 6 & $\mathrm{PPI}+$ amoxicillin 7 days followed by PPI + clarithromycin + nitroimidazole 7 days (sequential treatment) \\
7 & $\mathrm{Amoxicillin} 7$ days followed by PPI + amoxicillin + nitroimidazole 7 days (sequential treatment) \\
\hline 8 & $\mathrm{PPI}+$ levofloxacin + amoxicillin 14 days (levofloxacin-based triple treatment) \\
\hline 9 & $\mathrm{PPI}+$ clarithromycin + amoxicillin + probiotics (probiotic supplemented triple treatment) \\
\hline
\end{tabular}

TABLE 1: Drug regimens used in the study

PPI: proton pump inhibitor

After two weeks of treatment, participants were interviewed on whether they completed the treatment and, if not, why they did not complete the treatment.

The data were analyzed using IBM Statistical Package for the Social Sciences (SPSS) Statistics for Windows, Version 22.0 (Armonk, NY: IBM Corp.). Descriptive data were calculated as mean, standard deviation, and percentage. We used the Chi-square test to analyze quantitative data, and $\mathrm{p} \leqslant 0.05$ was considered statistically significant.

\section{Results}

A total of 250 participants were included in the study, with 154 male patients (61.6\%) and 96 female patients (38.4\%). The study population's mean age was 36.7 years \pm 13.2 years. Table 2 shows the correlation between adverse effects and treatment compliance. Of 250 patients, 135 (54.0 \%) had adverse effects; 87 (64.4\%) patients had mild-to-moderate adverse effects $(\mathrm{p}=0.000)$ and in 49 patients $(19.6 \%)$, the adverse effects were so severe that they were unable to complete the treatment ( $\mathrm{p}<0.001$; odds ratio, $62.9 ; 95 \%$ confidence interval 8.5-464.7). Compliance was better in males, i.e., 130 (84.40\%) as compared to females 71 (74\%) which was significant statistically $(\mathrm{p}=0.04)$. The association between treatment compliance and adverse effects is also statistically significant, and the odds of compliance are 62.9 times higher in patients who did not experience adverse effects compared to those who experienced adverse effects. 


\section{Cureus}

\begin{tabular}{|l|lll|l|l|}
\hline Adverse effect & \multicolumn{2}{l}{ Treatment compliance } & Total & p-Value & Odds ratio with 95\% confidence interval \\
\cline { 2 - 4 } & Yes & No & & & \\
\hline No & $114(99.1 \%)$ & $1(0.9 \%)$ & $115(46.0 \%)$ & & \\
Yes & $87(64.4 \%)$ & $48(35.6 \%)$ & $135(54.0 \%)$ & & \\
Total & $201(80.4 \%)$ & $49(19.6 \%)$ & 250 & & \\
\hline
\end{tabular}

\section{TABLE 2: Association of adverse effects with treatment compliance}

PPI: proton pump inhibitor

A descriptive analysis of different types of adverse effects and cross-tabulation of each with treatment compliance is shown in Table 3. The lowest compliance occurred in patients with diarrhea, followed by patients reporting abdominal/epigastric pain. Diarrhea was found in 26 cases (10.4\%), of whom half (50\%) could not complete the $\mathrm{H}$. pylori eradication therapy. Compliance was relatively much better with patients experiencing other adverse effects. Nausea with and without vomiting was observed in $1.6 \%$ of participants. Other adverse effects noted with $<1 \%$ frequency were dizziness, constipation, burning feet, anxiety, restlessness, and irritability in different drug combinations. The frequency comparison of patient compliance in various categories of adverse effects is statistically significant $(p<0.001)$.

\begin{tabular}{|c|c|c|c|c|}
\hline \multirow{2}{*}{ Detail of adverse effects } & \multicolumn{2}{|c|}{ Treatment compliance } & \multirow{2}{*}{ Total } & \multirow{2}{*}{ p-Value } \\
\hline & Yes & No & & \\
\hline Abdominal/epigastric pain & $22(52.4 \%)$ & $20(47.6 \%)$ & $42(16.8 \%)$ & \multirow{5}{*}{$<0.001$} \\
\hline Diarrhea & $13(50.0 \%)$ & $13(50.0 \%)$ & $26(10.4 \%)$ & \\
\hline Alteration in taste & $32(72.7 \%)$ & $12(27.3 \%)$ & $44(17.6 \%)$ & \\
\hline Headache with or without vomiting & $10(100.0 \%)$ & $0(0.0 \%)$ & $10(4 \%)$ & \\
\hline Miscellaneous & $10(76.9 \%)$ & $3(23.1 \%)$ & $13(5.2 \%)$ & \\
\hline
\end{tabular}

\section{TABLE 3: Association of various adverse effects with treatment compliance}

Table 4 presents the frequency and percentage of patients with and without adverse effects in different drug regimens. Drug regimen was significantly associated with adverse effects $(\mathrm{p}=0.002)$. Table 5 shows a detailed descriptive analysis of compliance and side effects in various drug regimens. Patient compliance in different drug regimen groups was not statistically significant $(\mathrm{p}=0.62)$. A comparison of treatment compliance in different genders showed poorer compliance in female participants than male participants ( $26 \%$ vs $15.60 \%$; $\mathrm{p}=0.05$ ). The frequency comparison of patients with compliance among different drug regimen groups was statistically nonsignificant at a p-value of 0.62 . 


\section{Cureus}

\begin{tabular}{|c|c|c|c|}
\hline \multirow{2}{*}{ Drug regimen } & \multicolumn{2}{|l|}{ Side effects } & \multirow{2}{*}{ p-Value } \\
\hline & Yes & No & \\
\hline PPI + clarithromycin + amoxicillin & $30(71.4 \%)$ & $12(28.6 \%)$ & \multirow{9}{*}{0.002} \\
\hline PPI + amoxicillin + metronidazole & $11(55.0 \%)$ & $9(45.0 \%)$ & \\
\hline PPI + bismuth + doxycycline + amoxicillin + nitroimidazole & $10(43.5 \%)$ & $13(56.5 \%)$ & \\
\hline PPI + clarithromycin + amoxicillin + nitroimidazole & $23(54.8 \%)$ & $19(45.2 \%)$ & \\
\hline PPI + amoxicillin 7 days followed by PPI + clarithromycin + nitroimidazole 7 days & $13(65.0 \%)$ & $7(35.0 \%)$ & \\
\hline PPI + amoxicillin 7 days followed by PPI + amoxicillin + nitroimidazole 7 days & $12(60.0 \%)$ & $8(40.0 \%)$ & \\
\hline PPI + levofloxacin + amoxicillin 14 days & $11(37.9 \%)$ & $18(62.1 \%)$ & \\
\hline Levofloxacin + PPI + amoxicillin 7 days followed by fluoroquinolones+ PPI + nitroimidazole & $22(64.7 \%)$ & $12(35.3 \%)$ & \\
\hline PPI + clarithromycin + amoxicillin + probiotics & $3(15.0 \%)$ & $17(85.0 \%)$ & \\
\hline
\end{tabular}

\section{TABLE 4: Association of drug regimen with adverse effects}

PPI: proton pump inhibitor

\begin{tabular}{|c|c|c|c|c|}
\hline Drug regimen & Compliance & Side effects & Frequency & $\begin{array}{l}\text { Percent } \\
(\%)\end{array}$ \\
\hline \multirow{9}{*}{ PPI + clarithromycin + amoxicillin; Total: 42} & \multirow{5}{*}{$\begin{array}{l}\text { Yes; Total: } 32 \\
(76.2 \%)\end{array}$} & No side effect & 11 & 34.4 \\
\hline & & Abdominal/epigastric pain & 5 & 15.6 \\
\hline & & Diarrhea & 1 & 3.1 \\
\hline & & Alteration in taste & 12 & 37.5 \\
\hline & & Miscellaneous & 3 & 9.4 \\
\hline & \multirow{4}{*}{$\begin{array}{l}\text { No; Total: } 10 \\
(23.8 \%)\end{array}$} & No side effect & 1 & 10.0 \\
\hline & & Abdominal/epigastric pain & 6 & 60.0 \\
\hline & & Diarrhea & 1 & 10.0 \\
\hline & & Alteration in taste & 2 & 20.0 \\
\hline \multirow{11}{*}{ PPI + amoxicillin + metronidazole; Total: 20} & \multirow{5}{*}{$\begin{array}{l}\text { Yes; Total: } 16 \\
(80.0 \%)\end{array}$} & No side effect & 9 & 56.3 \\
\hline & & Abdominal/epigastric pain & 2 & 12.5 \\
\hline & & Diarrhea & 1 & 6.3 \\
\hline & & Alteration in taste & 2 & 12.5 \\
\hline & & $\begin{array}{l}\text { Headache with or without } \\
\text { vomiting }\end{array}$ & 2 & 12.5 \\
\hline & \multirow{3}{*}{$\begin{array}{l}\text { No; Total: } 4 \\
(20.0 \%)\end{array}$} & Abdominal/epigastric pain & 1 & 25.0 \\
\hline & & Diarrhea & 2 & 50.0 \\
\hline & & Alteration in taste & 1 & 25.0 \\
\hline & & No side effect & 13 & 76.5 \\
\hline & & Abdominal/epigastric pain & 1 & 5.9 \\
\hline & $(73.9 \%)$ & Diarrhea & 1 & 5.9 \\
\hline \multicolumn{2}{|l|}{ PPI + bismuth + doxycycline + amoxicillin + nitroimidazole; Total: 23} & $\begin{array}{l}\text { Headache with or without } \\
\text { vomiting }\end{array}$ & 2 & 11.8 \\
\hline
\end{tabular}




\section{Cureus}

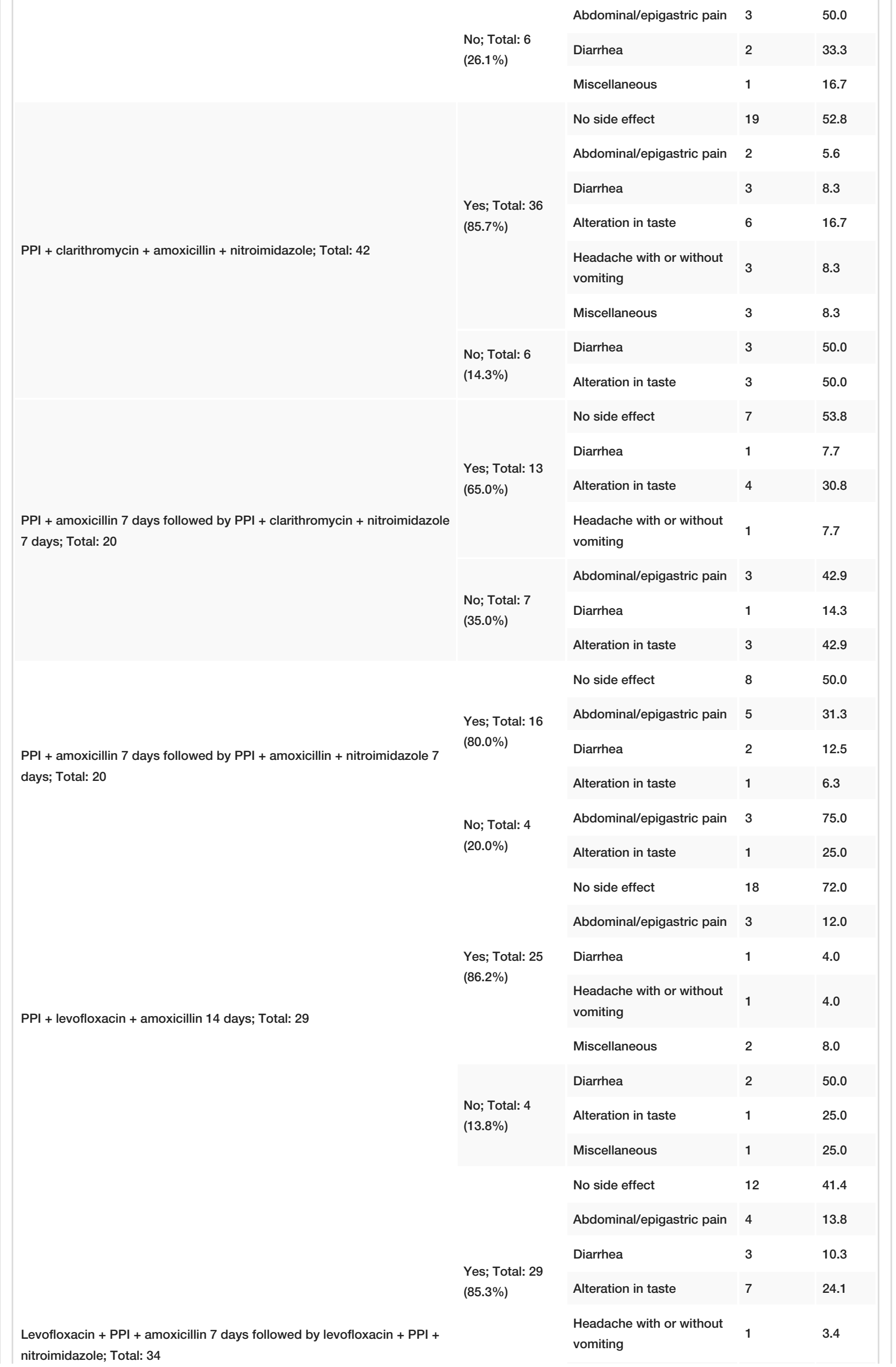




\section{Cureus}

\begin{tabular}{|c|c|c|c|c|}
\hline & & Miscellaneous & 2 & 6.9 \\
\hline & \multirow{4}{*}{$\begin{array}{l}\text { No; Total: } 5 \\
(14.7 \%)\end{array}$} & Abdominal/epigastric pain & 1 & 20.0 \\
\hline & & Diarrhea & 2 & 40.0 \\
\hline & & Alteration in taste & 1 & 20.0 \\
\hline & & Miscellaneous & 1 & 20.0 \\
\hline \multirow{2}{*}{ PPI + clarithromycin + amoxicillin + probiotics; Total: 20} & $\begin{array}{l}\text { Yes; Total: } 17 \\
(85.0 \%)\end{array}$ & No side effect & 17 & 100.0 \\
\hline & $\begin{array}{l}\text { No; Total: } 3 \\
(15.0 \%)\end{array}$ & Abdominal/epigastric pain & 3 & 100.0 \\
\hline
\end{tabular}

TABLE 5: Descriptive analyses of compliance and side effects in various drug regimens

PPI: proton pump inhibitor

\section{Discussion}

One of the important contributors to any therapy's success is adherence and compliance to the treatment regimen. The same is true for patients undergoing $\mathrm{H}$. pylori eradication therapy. Noncompliance is responsible for the failure of therapy in antibiotic-sensitive patients and can lead to antibiotic resistance. This can have long-term implications, and therefore, clinicians need to have a clear understanding of patients' reasons for noncompliance. This can be multifactorial, but adverse effects associated with the drugs play an important role. These factors have been discussed in several studies. In all these studies, intolerance to drugs comprises an important factor in treatment failure [13-15].

In our study, 50\% of patients had adverse effects with the drug combinations of amoxicillin, metronidazole, and clarithromycin, and $24 \%$ of patients taking levofloxacin with those antibiotics. This rate of adverse effects is the same as that reported in a meta-analysis by Fischbach et al., who reported that $50 \%$ of patients had adverse effects with one of the triple regimens [16].

The frequency of adverse effects in patients treated with clarithromycin was higher (74\%) than those treated with metronidazole, amoxicillin, and PPI (55\%), which was also higher than adverse effects in patients treated with bismuth-based quadruple therapy (43\%). Luther et al. did not find any difference in these two regimens for compliance, tolerance, and efficacy [17]. GI adverse effects like nausea, vomiting, diarrhea, and abdominal pain were reported in $1 \%$ to $14 \%$ in the clarithromycin and azithromycin individual treatment groups, but the frequency was be increased (76\%) when used in combination with other antibiotics.

Medicines like macrolides and metronidazole can lead to a metallic taste in the mouth, and they are excreted in saliva through diffusion or carrier-mediated transport. This effect's proposed mechanism is drug-receptor interaction and a disturbance in the action potential propagation in afferent and efferent neurons [18]. We found an alteration of taste in $30.8 \%$ of patients receiving sequential therapy.

The levofloxacin-based triple and sequential treatments have an equal ratio of tolerance, adverse effects, and maximum completion rate. The unpleasant metallic taste (4\%) and diarrhea (15\%) experienced by patients receiving levofloxacin-based treatment were due to metronidazole and amoxicillin, respectively [19-21].

Probiotics are live microorganisms that are host-friendly and offer health benefits. Commonly used probiotic bacteria Lactobacillus and Bifidobacterium improve H. pylori eradication and reduce adverse effects [22-24]. With the addition of probiotics, the tolerance to the clarithromycin-based triple regimen increased to $>85 \%$ in our study, and GI symptoms reduced from $76 \%$ in the standard triple regimen to $15 \%$ ( $\mathrm{p}=0.002)$. Antibiotic-associated diarrhea has been documented with certain antibiotics like clindamycin, cephalosporin, and amoxicillin-clavulanate and occurs due to clostridium difficile bacterial overgrowth leading to pseudomembranous colitis [25].

Poor tolerance to H. pylori therapies was more common among female patients (26\%) than male participants in our study (15.6\%; $\mathrm{p}=0.05)$. Yokota et al. reported a marginally significant association between male gender and self-interruption of therapy, contrary to our results [26].

Our study had several important limitations and is not absolutely blind, and the design allowed patients to opt-out of a particular regimen based on past experience with any specific drug. In addition, we lack the availability of drug sensitivity testing. However, despite these limitations, our study is unique in that it compared noncompliance due to adverse effects among nine eradication regimens. Previously published 
studies were limited in comparing only three to five eradication regimens $[27,28]$.

\section{Conclusions}

H. pylori infection has long-term implications. To avoid antibiotic resistance in the future and improve patient compliance, clinicians need to clearly understand the factors associated with intolerance to the various regimens.

Levofloxacin-based triple, sequential, concomitant, and standard triple treatment with probiotics have maximum tolerance and compliance with a completion rate of more than $85 \%$ with lesser side effects. Sequential treatment of standard three antibiotics has the least completion rate of $65 \%$ because of severe metallic distaste. However, further studies are required to strengthen the study.

\section{Additional Information}

\section{Disclosures}

Human subjects: Consent was obtained or waived by all participants in this study. Ethical Committee Pak Emirates Military Hospital Rawalpindi issued approval A/28/EC/223/20. Animal subjects: All authors have confirmed that this study did not involve animal subjects or tissue. Conflicts of interest: In compliance with the ICMJE uniform disclosure form, all authors declare the following: Payment/services info: All authors have declared that no financial support was received from any organization for the submitted work. Financial relationships: All authors have declared that they have no financial relationships at present or within the previous three years with any organizations that might have an interest in the submitted work. Other relationships: All authors have declared that there are no other relationships or activities that could appear to have influenced the submitted work.

\section{Acknowledgements}

The authors would like to thank the staff and doctors who helped in the collection of data.

\section{References}

1. Hooi JKY, Lai WY, Ng WK, et al.: Global prevalence of Helicobacter pylori infection: systematic review and meta-analysis. Gastroenterology. 2017, 153:420-429. 10.1053/j.gastro.2017.04.022

2. Graham DY: History of Helicobacter pylori, duodenal ulcer, gastric ulcer and gastric cancer . World J Gastroenterol. 2014, 20:5191-5204. 10.3748/wjg.v20.i18.5191

3. Nagy P, Johansson S, Molloy-Bland M: Systematic review of time trends in the prevalence of Helicobacter pylori infection in China and the USA. Gut Pathog. 2016, 8:8. 10.1186/s13099-016-0091-7

4. Marshall BJ, Warren JR: Unidentified curved bacilli in the stomach of patients with gastritis and peptic ulceration. Lancet. 1984, 1:1311-1315. 10.1016/s0140-6736(84)91816-6

5. Mladenova I, Durazzo M: Transmission of Helicobacter pylori . Minerva Gastroenterol Dietol. 2018, 64:251254. 10.23736/S1121-421X.18.02480-7

6. Diaconu S, Predescu A, Moldoveanu A, Pop CS, Fierbințeanu-Braticevici C: Helicobacter pylori infection: old and new. J Med Life. 2017, 10:112-117.

7. Chey WD, Leontiadis GI, Howden CW, Moss SF: ACG clinical guideline: treatment of Helicobacter pylori infection. Am J Gastroenterol. 2017, 112:212-239. 10.1038/ajg.2016.563

8. Malfertheiner P, Mégraud F, O'Morain C, et al.: Current concepts in the management of Helicobacter pylori infection--the Maastricht 2-2000 Consensus Report. Aliment Pharmacol Ther. 2002, 16:167-180. 10.1046/j.1365-2036.2002.01169.x

9. Shakya Shrestha S, Bhandari M, Thapa SR, Shrestha R, Poudyal R, Purbey B, Gurung RB: Medication adherence pattern and factors affecting adherence in Helicobacter pylori eradication therapy. Kathmandu Univ Med J (KUMJ). 2016, 14:58-64.

10. Li BZ, Threapleton DE, Wang JY, et al.: Comparative effectiveness and tolerance of treatments for Helicobacter pylori: systematic review and network meta-analysis. BMJ. 2015, 351:h4052. 10.1136/bmj.h4052

11. Allam MA, El-Shafie AM, Elwan AM, Soliman GM, Abu-Alfotuh A, Al Shabrawi H: Haematological side effect of Helicobacter pylori eradication. J Egypt Soc Parasitol. 2010, 40:583-590.

12. Peng C, Hu Y, Ge ZM, Zou QM, Lyu NH: Diagnosis and treatment of Helicobacter pylori infections in children and elderly populations. Chronic Dis Transl Med. 2020, 5:243-251. 10.1016/j.cdtm.2019.12.003

13. O'Connor JP, Taneike I, O'Morain C: Improving compliance with helicobacter pylori eradication therapy: when and how?. Therap Adv Gastroenterol. 2009, 2:273-279. 10.1177/1756283X09337342

14. Qasim A, O'Morain CA: Review article: treatment of Helicobacter pylori infection and factors influencing eradication. Aliment Pharmacol Ther. 2002, 16:24-30. 10.1046/j.1365-2036.2002.0160s1024.x

15. Houben MH, van de Beek D, Hensen EF, de Craen AJ, Rauws EA, Tytgat GN: A systematic review of Helicobacter pylori eradication therapy--the impact of antimicrobial resistance on eradication rates. Aliment Pharmacol Ther. 1999, 13:1047-1055. 10.1046/j.1365-2036.1999.00555.x

16. Fischbach LA, van Zanten S, Dickason J: Meta-analysis: the efficacy, adverse events, and adherence related to first-line anti-Helicobacter pylori quadruple therapies. Aliment Pharmacol Ther. 2004, 20:1071-1082. 10.1111/j.1365-2036.2004.02248.x

17. Luther J, Higgins PD, Schoenfeld PS, Moayyedi P, Vakil N, Chey WD: Empiric quadruple vs. triple therapy for primary treatment of Helicobacter pylori infection: systematic review and meta-analysis of efficacy and tolerability. Am J Gastroenterol. 2010, 105:65-73. 10.1038/ajg.2009.508 


\section{Cureus}

18. Zuckerman JM: Macrolides and ketolides: azithromycin, clarithromycin, telithromycin. Infect Dis Clin North Am. 2004, 18:621-649. 10.1016/j.idc.2004.04.010

19. Lee N, Duan H, Hebert MF, Liang CJ, Rice KM, Wang J: Taste of a pill: organic cation transporter-3 (OCT3) mediates metformin accumulation and secretion in salivary glands. J Biol Chem. 2014, 289:27055-27064. 10.1074/jbc.M114.570564

20. Hernández Ceruelos A, Romero-Quezada LC, Ruvalcaba Ledezma JC, López Contreras L: Therapeutic uses of metronidazole and its side effects: an update. Eur Rev Med Pharmacol Sci. 2019, 23:397-401. 10.26355/eurrev 20190116788

21. Akhavan BJ, Khanna NR, Vijhani P: Amoxicillin. StatPearls Publishing, Treasure Island, FL; 2021. https://www.ncbi.nlm.nih.gov/books/NBK482250/.

22. Lu C, Sang J, He H, et al.: Probiotic supplementation does not improve eradication rate of Helicobacter pylori infection compared to placebo based on standard therapy: a meta-analysis. Sci Rep. 2016, 6:23522. 10.1038/srep23522

23. Ruggiero P: Use of probiotics in the fight against Helicobacter pylori . World J Gastrointest Pathophysiol. 2014, 5:384-391. 10.4291/wigp.v5.i4.384

24. Goderska K, Agudo Pena S, Alarcon T: Helicobacter pylori treatment: antibiotics or probiotics . Appl Microbiol Biotechnol. 2018, 102:1-7. 10.1007/s00253-017-8535-7

25. Giannelli FR: Antibiotic-associated diarrhea. JAAPA. 2017, 30:46-47. 10.1097/01.JAA.0000524721.01579.c9

26. Yokota N, Ae R, Amenomori M, et al.: Clinical background factors affecting outcomes of Helicobacter pylori eradication therapy in primary care. J Gen Fam Med. 2019, 20:139-145. 10.1002/jgf2.245

27. Scaccianoce G, Hassan C, Panarese A, Piglionica D, Morini S, Zullo A: Helicobacter pylori eradication with either 7-day or 10-day triple therapies, and with a 10-day sequential regimen. Can J Gastroenterol. 2006, 20:113-117. 10.1155/2006/258768

28. Gasparetto M, Pescarin M, Guariso G: Helicobacter pylori eradication therapy: current availabilities. ISRN Gastroenterol. 2012, 2012:186734. 10.5402/2012/186734 